\title{
Research on Small-class Teaching About Programming Courses
}

\author{
Yanqin Tang \\ College of Command Information and Systems \\ PLA University of Science and Technology \\ Nanjing, China \\ nj_tyq@sina.com
}

\author{
Qing Li, Yongfen Wu \\ College of Command Information and Systems \\ PLA University of Science and Technology \\ Nanjing, China
}

\begin{abstract}
The most essential feature is paying attention to students' individual development optimization in small-class teaching, this paper mainly studies how to carry out small-class teaching in the programming courses. Combined with the actual situation of college computer teaching, we put forward some constructive suggestions and specific measures on curricula which take the lead in carrying out small-class teaching, how to implement small-class teaching, how to apply small-class teaching concept and teaching evaluation.
\end{abstract}

Keywords-Computer science, small-class teaching, Teaching concept, programming course

\section{INTRODUCTION}

The so-called "small-class teaching" refers to reduce the unit numbers of classes, that is reducing class size, increasing the proportion of teachers and students, which make the teacher put more effort for each student, thereby effectively improving the quality of education and student achievement [1]。

In 1970s American Gene.V.Glass and Mary.L.Smith conducted in-depth study between class size and student achievement for many years, drawn as shown in Figure 1[2]。

The curve shows that class size and learning achievement in inverse proportion. As the class size in the shrinking, student achievement will also increase. Visibly, class size and student achievement are closely related, greatly reducing school class size will make learning achievement get great results. Especially when the class size reduced to below 20, student achievement increased rapidly, the small class teaching effect will be more obviously.

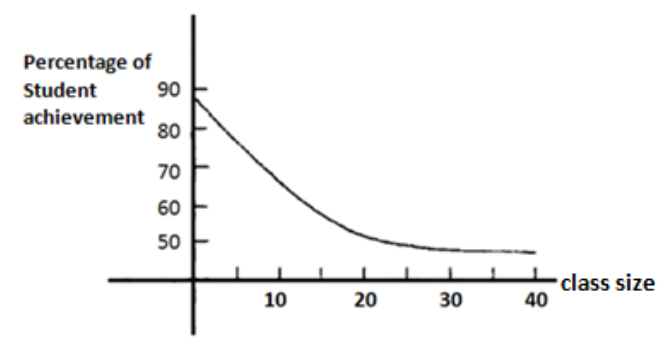

Fig 1 the relationship curve of class size and student achievement

But whether the decrease of the number of students means small-class teaching? Small class is a teaching form which is of fewer students, all teaching activities in the space are all belong to small class teaching, but it is not necessarily the small-class teaching. Small-class teaching is not only corresponding to the reduction of the number of students, but also the most essential feature is paying close attention to students' individual development optimization and carry out teaching organization, teaching content, teaching mode, teaching method, teaching evaluation for each individual student, the teacher should teach students in accordance with their aptitude. How to reach these request, we should comprehensive consider the corresponding teaching ideas, teaching methods, teaching evaluation and other aspects.

\section{WHICH SHOULD TAKE THE LEAD}

With the gradual popularization of small-class teaching, the school undoubtedly needs more number of teachers, classrooms, teaching facilities and funding for education, therefore, we can take some compromise measure in the existing conditions.

1) Computer practice course and exercise or answer class can take the lead in the implementation of small-class teaching.

Practice course and exercises answer class are the most effective means to consolidate the basis of knowledge, which using adequate teaching assistants to guide students targeted on the accumulated problems, which can not only solve the problem of teacher deficiency in initial small-class teaching, but also easy to resonate with students' thinking to find apt and specific ways to solve problems, and play the best results in the students' practice ability and innovation ability. Optional teaching staff should make full preparations, and take into account various difficulties and problems, such as assistants input time, energy and infrastructure, the professional direction graduate of this course is the best choice. In addition, teachers should exchange experience with teaching staff, combined with their own experiences to guide teaching staff to implement small-class teaching principle and examine assistants' preparation timely.

2) Trying to reform the course structure, reform part required course as elective course, carry out small-class teaching in major basic courses.

Quality education in computer should be put quality before quantity, special before much. As long as the students grasp the core knowledge and scientific 
way of thinking in the computer science, they can broaden their knowledge through elective course or self-study, and further interdisciplinary vision for purpose. So we can consider change part of required course into elective course, reduce the number of required courses and implement small-class teaching on the key basic course.

The benefits of doing so in three respects: Firstly, the key basic course teaches mainly basic knowledge of computer science, small-class teaching can give students to lay a solid base in computer. Secondly, the key curriculum has been constructed mostly as quality course, teaching resources are very rich and the implementation of small-class teaching is of small difficulty. Lastly, small-class teaching only focusing on key basic courses conforms to our present school situation, which reduce the urgent needs to teachers.

\section{III.IMPLEMENTATION OF SMALL-CLASS TEACHING}

Small-class teaching has the characteristics of opening and flexibility, is no longer unchanged. The teacher should not only provide methodological support for students, but also help students to solve the difficulties that may be encountered at any time. Students are not learning passively, but to arouse initiative learning enthusiasm and cultivate autonomous learning consciousness. In the students' original foundation of knowledge, the teacher should guide students to explore the learning content with their own learning fashion and actively participate in classroom activities.

Firstly, the implementation of small-class teaching need study preparation, the teacher must preliminary understand each student's learning foundation and desired course learning objectives. With the progress of course, the teacher will grasp students' personal characteristics gradually and prepare lessons according to the actual situation. Secondly, the teacher should instruct students before class, only when the instruction coverage to every student, all students can actively participate in class activities. Finally, the teacher must conduct the teaching design, to design a successful teaching process, not only depends on the basic content of the materials, but need greatly enrich and supplement to teaching content.

The basic implementation steps in small-class teaching are as follows:

1) A brief review, check error and consolidate the base of the course. Review often takes the form of questions or exercise according to students learning situation, the level of difficulty corresponding to different levels of students.

2) Establish learning scene and stimulate learning desire. The teacher can tell about the limitations of prior knowledge so as to seek new breakthrough, or the teacher can also describe the importance and prospect of the new knowledge in the actual engineering and professional application.

3) The teacher plays the role of organizers and guidance etc, comprehensive use of instruction, elicitation, practice, discussion, COSPLAY and other teaching methods, topics should be built around a certain problem. The teacher should guide the students as the protagonist to experience the exploration process through all kinds of communication between the teachers and students or among students, at last teachers and students jointly promote teaching development.

4) Evaluation. On the review and summary of learning activities, helping students to melt new knowledge into the existing knowledge system, further put forward the new problem to promote thinking.

\section{IV.REFORM OF EVALUATION SYSTEM}

On the side of the students, the evaluation form which taking the exam as the center is inconsistent of small-class purpose. Examination evaluation only pays attention to results. In order to get better grades, most students take the direct means of assault and rote learning before examination, do not need to pay attention to experiment, inquiry, activities etc. In order to improve the students' enthusiasm of participation, the teacher should comprehensive evaluate all aspects of students, such as research, personality, the spirit of cooperation. During the teaching of computer course, the teacher need carefully collect the key information of student learning, such as homework, research records, project records, experimental reports, classroom test, etc. The teacher evaluates the students according to performance in different educational goal, guide students actively participate in research teaching and practice teaching.

On the side of the teachers, rather amount than quality evaluation index is not conducive to the implementation of small-class teaching, the school should formulate relevant policies to carry out teacher training system. Small-class training must pay attention to 3 aspects:

1) Don't ignore teaching characteristics between large and small class. Through learning theory, teaching observation, teaching design, environmental design, the teachers strengthen the understanding and grasp of small-class teaching, they are changed into teaching activity participants, outstanding culture students' ability to explore, personality and cooperation.

2) Don't ignore the difference between senior teachers and new teachers. Senior teachers should focus on renewal of idea and method improvement, because of lack of new educational ideas, new teachers need to learn how to adapt to the classroom environment and how to deal with practice details in small-class teaching.

3) Training funds must be used for its intended purpose. Small-class teaching reform is costly and training funds are flexible demand, therefore the use of funds should to be supervised.

In order to guarantee the small-class teaching quality, it is necessary to monitor the effect of small-class teaching and establish the teacher evaluation system to promote the reform of small-class teaching. The teachers have not only profound professional academic level, but also have 
small-class control ability. The teachers should have considerable teaching ability in several teaching aspects, such as imparting knowledge, research teaching, individualized training and team cooperation. In addition to teaching evaluation by supervision, we should take the way of student evaluation, such as evaluation of the teaching behavior, comprehensive evaluation of the classroom, as well as self evaluation to whether achieve the teaching goal.

\section{LARGE-CLASS REFERENCE SMALL-CLASS TEACHING PHILOSOPHY}

In the current environment, it is not realistic to small-class teaching to each course, but large-class teaching is not refuse the implementation small-class teaching concept. We are trying to integrate the small-class teaching concept into the large-class according to literature, which can be categorized into five:

1) Large class preparation, small class management: Prepare for large class and teaching into small class, several teachers teach on parallel.

2) Large class teaching, small group tutoring: The teacher centralized instruction, after-school many teachers or graduate students participate in learning guidance (such as discuss, answer, topic exploration, etc) to realize individual attention.

3) Centralized instruction, hierarchical teaching: Teachers make different teaching goals for different level of the students, organize different teaching contents, design different levels of problems and evaluation. At the same time, with the aid of modern teaching technology, let the teacher can observe learning feedback in different level students.

4) Grouping cooperation, multi-directional exchange: Partition students to multiple groups, through the cooperation in the group, group competition and communication with teachers, the students can fully understand the thought and teaching content, training team spirit.

5) Different method in the same class, on-demand streaming: According to the course content, parts of the contents are collective teaching, others are divided into classes or groups.

\section{VI.SUMMARIZE AND PROSPECT}

The development of society and technology have put forward new requirements for the cultivation of talents in Colleges and universities, the talent cultivation mode facing new challenges. In this circumstance, how to improve the level of talent training becomes the urgent problem to be solved. Take small-class teaching and promote the international advanced teaching method is one of the effective ways to solve the problem. Therefore we put forward some constructive opinions, such as small-class teaching take the lead in computer experiment and exercise course, focusing on basic course, establishing a plurality of small-class teaching evaluation system. Practice show these methods achieved some good results in small-class teaching.
In short, small class education reform is a long-term and arduous comprehensive engineering, which need the joint efforts of school, teachers and students to promote the reform.

\section{ACKNOWLEDGMENT}

I thank my family for my life to take care of, so I do not worry about. Thanks to my department colleagues of concern.

\section{REFERENCES}

[1] YiPu Han. New Views On Superiority Of Smaller Classes Teaching, Journal of Yichun University, 2005.

[2] Glass, G.V., Cahen, L.S., Mary Lee .S. \& Filby, N.N.. School Class Size: Research and Policy[M]. NewYork : Sage Publication, 1982.

[3] Yanqin Tang, Jinsong Jiang, Weiwei Chen. Small-class Teaching Discuss About Programming Courses. 2011 IEEE International Symposium on IT in Medicine \& Education, 2011.12.

[4] XuePing Ma. Probe and analysis of small-class education reform in In Florida, World Education Information, 2012, No.2.

[5] ZhengYu Li. Reflections on the problems of the small-class education, Educational Practice and Research, 2012.3A:8-10.

[6] ShouXuan Yan, NingBo Zhu. The dilemma and outlet in small-class teaching practice, Journal of the Chinese Society of Education, 2011.12:5-8 